\title{
Panorama dos modelos de negócios de periódicos científicos da área de Comunicação e Informação: classificação Qualis A1
}

\author{
Overview of the business models of scientific journals in the Communication and Infor- \\ mation area: Qualis A1 classification
}

\author{
Amanda Fernandes Marques \\ Mestranda em Ciência da Informação \\ Universidade Federal do Rio Grande do Sul \\ fm.amanda@hotmail.com
}

\begin{abstract}
Resumo
Investiga os modelos de negócio dos periódicos científicos da área de Comunicação e Informação classificadas como Qualis A1 de acordo com o sistema Qualis Periódicos da Plataforma Sucupira. Objetiva verificar como esses periódicos captam recursos para manter sua publicação continuada. Averigua se na literatura sobre o assunto há alguma classificação sobre os modelos de negócios para periódicos científicos eletrônicos e em quais tipos os periódicos listados se encaixam. Apresenta um breve referencial teórico sobre periódicos científicos e como eles são avaliados no Brasil, além de abordar sobre modelos de negócios para periódicos científicos eletrônicos. Detalha na metodologia seu caráter quantitativo ao listar os periódicos encontrados, o modo da coleta de dados realizado na Plataforma Sucupira e identificação das limitações da pesquisa. Retrata os dados coletados em forma de quadro, mostrando informações como nome do periódico, país, vínculo com Universidade ou editora, modelo de negócio. Aponta em seus resultados finais que o modelo tradicional de assinaturas ainda é predominante, destacando também que países da América Latina e Central investem no acesso aberto com fomentos à pesquisa por meio de recursos públicos. Finaliza afirmando que apesar da pouca variabilidade dos modelos de negócios, o mercado editorial aos poucos repensa suas taxas de publicação.
\end{abstract}

\section{Palavras-chave}

Periódicos científicos eletrônicos. Qualis Periódicos. Comunicação e Informação. Modelos de negócio.

\begin{abstract}
It investigates the business models of scientific journals in the field of Communication and Information classified as Qualis A1 according to the Qualis Periodicals system of the Sucupira Platform. It aims to verify how these periodicals raise funds to maintain their continued publication. It explores whether in the literature on the subject there is any classification of business models for electronic scientific journals and in which types the listed periodicals fit. It presents a brief theoretical framework on scientific journals and how they are taken in Brazil, in addition to addressing business models for electronic scientific journals. The methodology details its quantitative character by listing the journals found, the method of data collection carried out on the Sucupira Platform and identification of the research's limitations. It depicts the data collected in the form of a table, showing information such as the name of the journal, country, link with an University or publisher, business model. In its final results, it points out that the traditional subscription model is still predominant, also highlighting those countries in Latin and Central America invest in open access, fostering research through public
\end{abstract}


resources. It concludes by stating that despite the little variability of business models, the publishing market is slowly rethinking its publication fees.

\section{Keywords}

Electronic scientific journals. Qualis Periodicals. Communication and Information. Business models.

\section{INTRODUÇÃO}

Um dos principais meios de comunicação entre os cientistas para divulgar os resultados de suas pesquisas é o periódico científico. Através dos tempos, apesar do suporte do periódico ter mudado devido às tecnologias desenvolvidas, o sistema tradicional de publicação científica pouco se reinventou (GUMIEIRO; COSTA, 2012). Ainda se segue o mesmo caminho para publicar um artigo, e Johnson (2002, online apud LEITE, 2006, p. 85) afirma que, apesar de toda tecnologia informacional disponível, o clássico processo de publicação "limita, mais do que expande a disponibilidade e legibilidade (readership) da maior parte da pesquisa científica (ao tempo que obscurece suas origens institucionais)".

Publicar é essencial para que a comunicação científica ocorra. Como na fala de Meadows (1999), que declara que essa troca de conhecimento é importante para comunicação científica, e Ziman (1979), que sustenta que o conhecimento só é válido quando compartiIhado. Portanto, o acesso à informação científica deve ser livre de impedimentos, sejam eles de acesso ou financeiro.

Porém, mesmo com iniciativas como o movimento de acesso aberto, canais de comunicação científica como os periódicos precisam de recursos para se manter e sobreviver. São inúmeros profissionais envolvidos, bem como utilização de infraestrutura para que o processo de editoração se execute. $O$ que acaba levantando as seguintes questões: como, em tempos em que se levanta a bandeira do acesso livre à informação, pode-se manter um periódico ativo e contínuo? De que modo pode-se captar recursos para manter a qualidade de um periódico e dar acesso livre à informação?

Dessa forma, o presente artigo investiga quais modelos de negócios são utilizados pelos periódicos avaliados como Qualis A1 da área de Comunicação e Informação para obter financiamento e então assim, permanecerem ativos. O recorte metodológico justifica-se pelo alto prestígio que periódicos classificados como A1 possuem, e do delineamento do campo por ser um assunto intrínseco da área.

\section{PERIÓDICOS CIENTÍFICOS ELETRÔNICOS E AVALIAÇÃO QUALIS}

Para que um pesquisador possa tanto publicar seu trabalho quanto se atualizar a respeito de outras pesquisas, é necessário que se faça a divulgação da ciência produzida. Apesar de cada área do conhecimento possuir suas peculiaridades na maneira de trocar informações sobre seus trabalhos, é indiscutível que o suporte mais utilizado seja o periódico científico. O periódico se diferencia dos outros veículos de comunicação científica pelos seguintes elementos: possui maior agilidade e regularidade nas publicações, como também a reunião dos resultados de pesquisas em um local só, tornando o avanço científico mais eficaz (ZIMAN, 1979). 
A comunicação científica realizada através dos periódicos vem sofrendo transformações com relação ao seu suporte. Essas mudanças surgiram da necessidade de padronizar os artigos publicados, avaliar a qualidade dos trabalhos recebidos e superar a barreira física de distribuição, ou seja, tornar a comunicação científica mais eficiente (MEADOWS, 1999). O pesquisador Frederik Lancaster em 1977 já previa essa necessária transição de suportes, declarando que no século XXI os cientistas já teriam ultrapassado os impasses geográficos através da criação de ferramentas tecnológicas que os auxiliariam na produção e distribuição dos seus trabalhos científicos (SIMEÃO, 2001).

Ao longo dos anos, os periódicos científicos passaram por melhorias em seus processos. A partir dos anos 70, essas benfeitorias se iniciaram através da presença e utilização dos computadores. A datar dos anos 80 , os computadores tornaram-se cada vez mais necessários para as mais diversas atividades, transformando-se em objetos pessoais - como os computadores de mesa. É evidente que isso também influenciou processos relacionados aos periódicos científicos, como armazenamento de informações e editoração de textos (STUMPF, 1996). As etapas para a elaboração de um periódico científico se tornaram mais ágeis, mas não impediram a crise que estava por vir.

Até este momento no formato impresso, a crise dos periódicos, ainda na década de 80, ocorreu pelo alto custo das assinaturas, sendo dispendioso manter essas subscrições tanto por assinantes individuais quanto por bibliotecas. Pela dificuldade de acesso a essas publicações, por consequência, essas assinaturas diminuíram. Sendo as assinaturas a majoritária fonte de renda dos periódicos, o lucro das editoras diminuiu, impulsionando alternativas, como o acesso aos artigos científicos através da internet. Outra crise, percebida por Biojone (2003, p. 133), surge dos seguintes problemas: "Ientidão na divulgação da informação, falta de pontualidade na publicação, circulação muito baixa nos meios científicos internacionais, e, por isso, a falta de visibilidade da produção científica". Ainda seguro a autora, a transição do impresso para o eletrônico proporcionou soluções para estes problemas. Para a ela, "os periódicos científicos eletrônicos surgiram como solução para algumas dessas adversidades.

Na década seguinte, a ocorrência desse conjunto de fatos estimulou novos caminhos para a comunicação científica. Através da internet, é possível romper barreiras físicas para a divulgação científica, incentivando maior acesso aos trabalhos publicados de forma online. Meadows (1999 apud BARCELLOS, 2006) em seus trabalhos "[...] já ressaltava que acesso a artigos científicos online é importante tanto para a disseminação de resultados de pesquisas quanto para o uso de recursos de informação online".

Como mencionado, apesar do periódico ter sofrido melhorias em seu suporte físico, passando do impresso para o eletrônico, a sua dinâmica editorial continua a mesma, apesar de mais rápida. De acordo com Barbosa et al. (2013), os periódicos eletrônicas possuem poucas diferenças quanto ao seu processo de editoração, e passam pelas mesmas etapas de um periódico tradicional: controle de qualidade, aderência de normas e avaliação pelos pares, recebendo também o mesmo crédito e notoriedade de um periódico em papel. Apesar de o processo editorial continuar o mesmo, o resultado final apresentado pelo suporte digital é maior: melhor recuperação de artigos, maior alcance, visibilidade superior e manuseio do documento (VANZ; SILVA FILHO, 2019).

Outra função importante atribuída aos periódicos científicos é a validação de uma pesquisa feita através da revisão por pares (peer review). Esse processo consiste no envio do artigo para um periódico de interesse do pesquisador e esse artigo será submetido a especialistas da área para avaliação. Através desse procedimento, a equipe editorial do periódico 
analisa, por meio desses avaliadores, se o artigo está de acordo com os propósitos do periódico, bem como se o texto em análise é qualificado para publicação. Se houver alguma divergência nas análises dos revisores, o trabalho será enviado a outros colaboradores para uma terceira opinião. Portanto, entende-se que esse sistema de revisão de originais também contribui para o refinamento da produção científica das áreas, pois, como Nassi-Caló (2015, online) afirma, essa atividade "[...] é tida pela grande maioria dos pesquisadores como o mecanismo mais efetivo e eficaz para garantir a qualidade, confiabilidade, integridade e consistência da literatura acadêmica.".

Assim como os artigos que são submetidos para publicação passam por um sistema de avaliação por pares, os periódicos científicos também são submetidos a análises e verificações. No Brasil, por exemplo, há o sistema Qualis Periódicos, utilizado para avaliar e classificar periódicos científicos usados pelos programas de pós-graduação (CA-PES, 2019?).

Vinculado a um órgão governamental chamado de Coordenação de Aperfeiçoamento de Pessoal de Nível Superior (CAPES), o sistema Qualis Periódicos foi implementado em 1998 como resposta para a necessidade de instrumentalizar e avaliar a produção científica dos programas de pós-graduação do Brasil (JACON, 2007). Através de critérios estabelecidos pela área e então aprovados pelo Conselho Técnico-Científico da Educação Superior (CTC-ES), o sistema Qualis Periódicos busca classificar os periódicos científicos conforme sua relevância para a área em que está inserida. Essa classificação é atualizada de forma anual e utiliza notas como indicadores de qualidade: A1 (nota mais elevada), A2; A3; A4; B1; B2; B3; B4; e C (equivalente a 0) (CAPES, 2019).

O periódico científico é um canal formal de comunicação para que cientistas comuniquem o resultado de suas pesquisas, portanto, como aferição de qualidade, os artigos devem passar por um sistema de avaliação antes de serem aceitos pela comunidade científica da área a que pertencem. Como afirmam Alvarez e Caregnato (2017, p. 23) "[...] a ciência como produto da humanidade é um fenômeno que precisa ser analisado periodicamente[...]", ou seja, a avaliação no âmbito da pesquisa deve ser considerada mais que um procedimento rotineiro a ser cumprido. Em sintonia com o que foi dito anteriormente, confirma Jacon (2007, p. 190) que "[...] para que uma pesquisa tenha valor científico, é necessário que ela seja avaliada e validada através da publicação em um canal formal de divulgação".

\section{MODELOS DE NEGÓCIO PARA PERIÓDICOS CIENTÍFICOS}

Antes do advento das tecnologias impulsionarem a mudança de suporte dos periódicos científicos, esses funcionavam através do sistema de assinaturas. Porém, no final da década de 1980, essa estrutura entrou em crise. De acordo com Costa e Guimarães (2010), as bibliotecas norte-americanas não tinham mais recursos para continuar assinando títulos, pois o preço de manter a subscrição dos periódicos se elevava cada vez mais. Apesar da migração de suporte, e consequentemente, a diminuição de custos, esse impasse financeiro seguiu para o meio digital, pois as editoras continuavam detendo o copyright dos artigos submetidos, garantindo o direito de leitura somente para os pagantes (MUELLER, 2006).

Esse colapso no sistema tradicional de comunicação científica foi o incentivo para as bibliotecas procurarem soluções alternativas para contornar essa recessão. Segundo Weitzel (2005, p. 2), há um conjunto de fatores que guiaram a busca por alternativas: 


\begin{abstract}
A busca por fluxos de comunicação científica mais eficientes, baratos e transparentes levou a comunidade científica a adotar novas formas para publicar seus produtos científicos a partir do domínio de uma tecnologia própria. Este processo resultou na alteração e controle da cadeia de produção, disseminação e uso do conhecimento científico registrado, antes exclusivo dos editores comerciais dos periódicos científicos.
\end{abstract}

O passo inicial para investigar alternativas foi em 1999, quando criou-se o conceito de Open Archives Initiative (OAI), estabelecida por Paul Ginsparg e colaboradores, durante uma convenção em Santa Fé, Novo México. Ainda conforme Weitzel (2005), o OAl pretendia incentivar o depósito de trabalhos pelos próprios autores, normalizar metadados, interoperabilidade entre arquivos e livre recuperação, compartilhamento e acesso à informação. Foi o primeiro ato para dar início ao movimento de acesso aberto. Este movimento é baseado no princípio da disseminação, fidedignidade e acessibilidade (BJÖRK, 2013).

A concepção do que é acesso aberto foi consolidado em 2001, no Budapest Open Archives Initiative (DEZ ANOS..., 2012, online), onde foi discutido o sistema de comunicação científica e suas problemáticas contemporâneas. Nesse evento, foi definido o conceito de acesso aberto:

\begin{abstract}
"Acesso aberto" à literatura científica revisada por pares significa a disponibilidade livre na Internet, permitindo a qualquer usuário ler, fazer download, copiar, distribuir, imprimir, pesquisar ou referenciar o texto integral desses artigos, recolhe-los para indexação, introduzi-los como dados em software, ou usá-los para outro qualquer fim legal, sem barreiras financeiras, legais ou técnicas que não sejam inseparáveis ao próprio acesso a uma conexão à Internet. As únicas restrições de reprodução ou distribuição e o único papel para o direito autoral neste domínio é dar aos autores o controle sobre a integridade do seu trabalho e o direito de ser devidamente reconhecido e citado.
\end{abstract}

De acordo com Harnad et al. (2001) $)^{1}$ essa iniciativa se apresenta através duas vias para que se alcance o acesso aberto por completo: a via verde, que trata sobre a publicação de artigos em periódicos que possuam modelos de negócio diferentes do acesso aberto e o autoarquivamento do artigo em repositórios de acesso aberto; e a via dourada, que se refere à publicação de artigos em periódicos de acesso aberto, ou seja, sem custo algum para o leitor acessá-las.

Porém, com relação à via dourada, para se criar e manter contínua a publicação de um periódico de acesso aberto são necessários investimentos e recursos. Conforme Abadal (2012, online, tradução nossa)2: "A sustentabilidade econômica [...] é outro dos desafios fundamentais para as revistas em acesso aberto hoje.". Ou seja, é necessário definir um modelo de negócios para que o periódico possa angariar capital e manter sua rotina periódica de publicações ativa

\footnotetext{
${ }^{1}$ There are two roads to OA: the "golden" road (publish your article in an OA journal) and the "green" road (publish your article in a non-OA journal but also self-archive it in an OA archive).

2 La sostenibilidad económica, el establecimiento de sólidas vías de ingresos que permitan sufragar los costes editoriales, los desarrollos tecnológicos de las plataformas digitales, etc., es otro de los retos fundamentales de las revistas en acceso abierto en la actualidad.
} 
Segundo Crow, (2009, p.5, tradução nossa)3 um modelo de negócio "descreve a lógica econômica que sustenta uma organização". O autor ainda complementa que, tratando-se de periódicos, há de se encontrar o denominador comum entre o oferecimento de serviços e conteúdo para seus leitores e os meios necessários para sustentar o processo de elaboração do periódico.

A tríade formada entre as tecnologias da informação e comunicação, o movimento pelo acesso aberto e a necessidade de ampliação de acesso ao conhecimento científico intensifica a discussão acerca dos modelos de negócios adotados pelos periódicos científicos. Como implementar o acesso aberto e ainda assim manter-se financeiramente? Apesar do debate em torno de tal assunto desestabilizar o modus operandi tradicional dos periódicos científicos, as vias componentes do acesso aberto não se desvinculam da necessidade de obtenção de capital para amparo. Há uma diferença na adoção de modelos de negócio entre periódicos de acesso aberto e periódicos tradicionais. Pereira e Furnival (2020), ao refletirem sobre as ideias de Crow (2009), Suber (2004) e Morrison et al. (2015), afirmam que os modelos voltados para o acesso aberto focam na oferta do serviço, ou seja, quem deseja conceder o acesso sem encargos financeiros deve arcar com os custos (seja o próprio autor, uma agência de fomento, um financiador privado, entre outros); enquanto os periódicos de características tradicionais têm seu foco na demanda, transferindo o ônus do acesso para quem o consome.

Nessa conjuntura são inseridos os modelos de negócio para periódicos científicos "[...] para manterem-se financeiramente e, concomitantemente, disponibilizarem suas publicações em acesso aberto e com qualidade" (BARCELLOS, 2016, p. 30). Por trás do editorial de um periódico científico, há inúmeros profissionais envolvidos - bibliotecários, tradutores, designers, setores de distribuição e outros. Toda essa linha de produção traz custos, sendo necessário que a equipe editorial procurar por maneiras de subsidiar essa cadeia. Com isso, é necessário que esse grupo de trabalho procure por um modelo de negócios para que o periódico continue sendo publicado. Além dos recursos humanos, há outros tipos de expensas como a inscrição no ISSN e a adoção de tecnologias que facilitem a "[...] acessibilidade, a recuperação de informações, navegabilidade e interatividade" (GUANAES; GUIMARÃES 2012, p. 63). Esse conjunto de recursos são imperativos, pois além da imprescindibilidade para a existência, continuidade e permanência do periódico científico, também são pontos que tornam o periódico um suporte de fontes de informações confiáveis. O formato eletrônico reduz alguns dispêndios, como o gasto da impressão de exemplares, porém os elementos previamente citados estão presentes tanto no formato eletrônico quanto no suporte físico e, mesmo ponderando perdas e ganhos, "a transição entre os suportes impresso e eletrônico, um processo que aponta para a hegemonia do eletrônico a curto prazo, não foge totalmente dos modelos tradicionais ainda vigentes no financiamento das revistas científicas" (GRUSZYNSKI; GOLIN, 2006, online).

$\mathrm{Na}$ literatura há inúmeros exemplos de modelos de negócios para periódicos científicos digitais e para o presente artigo serão utilizados os novos modelos de negócios de comunicação científica apontados por Swan (2016, p. 34):

\footnotetext{
${ }^{3} \mathrm{~A}$ business model describes the economic logic that sustains an enterprise.
} 
a) modelo institucional: a atividade é financiada pela instituição;

b) modelo comunitário: a atividade é financiada por meio de doações em dinheiro ou outra espécie de apoio por parte membros da comunidade;

c) modelo por patrocínio público: a atividade é financiada por subvenções regulares provenientes de um órgão público, tal como um órgão nacional responsável por TIC;

d) modelo por assinatura: a atividade é financiada comercialmente pelo pagamento de taxas de assinatura realizados por seus usuários;

e) modelo comercial: a atividade é financiada comercialmente pelo pagamento de taxas de assinatura e/ou anúncios publicitários.

Consoante com o modelo comercial, existe uma taxa já conhecida pelos envolvidos nos processos de publicações: as article processing charges (APC, taxas de processamento de artigos, tradução nossa). Essas taxas se fazem presentes nos cenários nos quais o periódico é totalmente no formato aberto, e essa taxa se manifesta através de encargos de submissão (como serviços de tradução, revisão ou a publicação em si); ou quando o periódico trabalha com cobranças para os que desejam ter acesso ao conteúdo, mas se o autor gostaria de deixar o seu trabalho em acesso aberto, é necessário pagar uma taxa (HOUSE OF COMMONS, 2004).

Elaborar um modelo de negócios que financie os custos de um periódico científico é vital para que sua circulação continue. Apesar da iniciativa do acesso aberto ter revolucionado e feito com que pesquisadores e editoras refletissem sobre o modelo tradicional, fazendo com que novos modelos fossem criados para que os periódicos pudessem se manter ativos, Crow (2009, p. 8, tradução nossa) ${ }^{4}$ menciona que os modelos não são absolutos e "estes modelos podem se combinar para maximizar os recursos disponíveis para apoiar um periódico". Ainda de acordo com o autor, há características a serem levadas em conta ao escolher o modelo de negócio ajustado ao periódico, como seu conteúdo, o formato da publicação, o público a ser atingido, nacionalidade e a possibilidade de financiamento para o desenvolvimento do periódico. Visando manter a sustentabilidade de um periódico, as fontes de financiamento desses terão de se diversificar conforme as mudanças de mercado e as necessidades dos seus clientes/usuários. A comunicação científica passou e vem passando por mudanças e os meios de subsistência de seus suportes, como o periódico científico, não serão excluídos dessas transformações, salientando a importância de ser constante a abordagem desse assunto.

\section{METODOLOGIA, PROCEDIMENTOS E COLETA DE DADOS}

A abordagem deste artigo é descritiva, pois tem o intuito de detalhar as características dos modelos de negócios de periódicos classificados como A1 na área de Comunicação e Informação. Caracteriza-se como uma pesquisa quantitativa, pois trabalha na identificação dos periódicos listados, bem como se assinala outras informações como país, vínculos e explicitação do modelo de negócios. A representação dessas informações dá-se em forma de quadro.

Para contextualizar o assunto proposto, bem como para análise dos dados quantitativos, essa pesquisa se apoiou na literatura já existente sobre o assunto, caracterizando o presente artigo como bibliográfico. A natureza básica do trabalho é destacada, pois se pretende investigar as particularidades dos modelos de negócios de periódicos científicos de

\footnotetext{
${ }^{4}$ In many cases, supply- and demand-side income models can be combined to maximize the income sources available to support a journal
} 
determinada área e determinada classificação, sem intenção alguma de aplicação prática.

O locus da pesquisa é a Plataforma Sucupira, através da seção Qualis Periódicos. Conforme definição disponibilizada pela CAPES (2019?), a Plataforma Sucupira "é o módulo que permite a classificação e consulta ao Qualis das áreas, bem como a divulgação dos critérios utilizados para classificação de periódicos".

A coleta de dados prosseguiu da seguinte forma: ao acessar o site da Plataforma Sucupira, selecionou-se a opção "Qualis" e após, "Qualis periódicos". A Plataforma Sucupira permite que o consulente refine sua pesquisa, dando as opções de busca "Evento de Classificação", "Área de Avaliação", "ISSN", "Título" e "Classificação". Para a execução da pesquisa, refinou-se a pesquisa através das seguintes seleções: classificações de periódicos do quadriênio 2013-2016 em "Evento de Classificação"; em "Área de Avaliação", selecionou-se a área de Comunicação e Informação; e na "Classificação" optou-se pela nota mais alta, A1. Desse modo, a pesquisa resultou na listagem de 55 periódicos. Para maior refinamento, exclui-se os periódicos impressos, deixando somente os periódicos de suporte digital, chegando no número final da pesquisa, 39 periódicos.

A identificação dos modelos de negócios foi feita através do acesso a cada um dos periódicos listados e a maioria das informações foi retirada de seções como "instruções aos autores" e "política de publicações". Quando não foi possível retirar os dados da pesquisa por esse caminho, utilizou-se o contato via e-mail com a equipe editorial do periódico.

A pesquisa também apresentou limitações. Com relação à identificação das características dos modelos de negócios do periódico Hermés, não foi possível coletar dados sobre se há algum tipo de captação de recursos para sua subsistência, tanto pelas vias de acesso ao periódico quanto via contato por e-mail.

\section{RESULTADOS E DISCUSSÕES}

No total, estão sendo exibidos os resultados concernentes a 39 periódicos. Suas informações estão divididas por nome, país a qual pertencem, se possuem vinculação com alguma Universidade ou editora e qual o modelo de negócio utilizado pelo periódico.

Em sua maioria, mais especificamente em 36 periódicos, foi possível localizar os modelos de negócios consultando os próprios sites. Porém, em três deles foi necessário contato via e-mail, visto que não foi viável encontrar tais informações em seus sites. Dois deles, o The South Atlantic Quarterly e Knowledge Organization responderam ao contato enviado com as devidas informações, que estão dispostas abaixo. Apenas um deles, o periódico Hermès, como dito anteriormente, não teve suas informações detalhadas, posto que o contato via e-mail não foi respondido e maiores informações não foram encontradas no site. Abaixo, em forma de quadro, está a apresentação dos dados coletados durante a pesquisa na Plataforma Sucupira através da seção Qualis Periódicos: 
Quadro 1 - Periódicos científicos da área de Comunicação e Informação: Qualis A1

\begin{tabular}{|c|c|c|c|}
\hline Nome / Local & Local & $\begin{array}{l}\text { Vínculo com Univer- } \\
\text { sidade ou editora? }\end{array}$ & Modelo de negócio \\
\hline $\begin{array}{l}\frac{\text { African Journal of Li- }}{\text { brary, Archives and }} \\
\text { Information Science. }\end{array}$ & Nigéria & $\frac{\text { Archlib \& Information }}{\text { Services Ltd. }}$ & $\begin{array}{l}\text { Sem APC. Paga-se para ter acesso aos arti- } \\
\text { gos e os preços variam conforme a renda do } \\
\text { país. Também trabalha através do sistema } \\
\text { de assinaturas. }\end{array}$ \\
\hline Biblios (Lima). & EUA & $\begin{array}{l}\text { University of Pitts- } \\
\text { burgh }\end{array}$ & $\begin{array}{l}\text { Sem APC. Gratuito para leitores. Agência de } \\
\text { fomento. }\end{array}$ \\
\hline$\frac{\text { Comunicar (Huelva. }}{\text { Internet). }}$ & Espanha & $\begin{array}{l}\text { Grupo Comunicar } \\
\text { Edições. }\end{array}$ & $\begin{array}{l}\text { Sem APC. Gratuito para leitores. Mantém-se } \\
\text { através de agência de fomento e também } \\
\text { por meio de assinaturas da versão impressa. }\end{array}$ \\
\hline$\frac{\text { Critical Studies in Media }}{\text { Communication. }}$ & Inglaterra & Taylor \& Francis. & $\begin{array}{l}\text { APC apenas para acesso aberto. É possível } \\
\text { pedir desconto conforme o nível do país do } \\
\text { autor. Mantém-se através de assinaturas. }\end{array}$ \\
\hline$\frac{\text { Dados - Revista de Ci- }}{\underline{\text { ências Sociais. }}}$ & Brasil & $\begin{array}{l}\text { Universidade Estadu- } \\
\text { al do Rio de Janeiro. }\end{array}$ & $\begin{array}{l}\text { Sem APC. Gratuito para leitores. Agência de } \\
\text { fomento. }\end{array}$ \\
\hline Digital Journalism. & Inglaterra & Taylor \& Francis. & $\begin{array}{l}\text { APC apenas para acesso aberto. É possível } \\
\text { pedir desconto conforme o nível do país do } \\
\text { autor. Mantém-se através de assinaturas. }\end{array}$ \\
\hline$\frac{\text { Discourse \& Communi- }}{\text { cation. }}$ & EUA & Sage publications. & $\begin{array}{c}\text { APC apenas para acesso aberto. Mantém-se } \\
\text { através de assinaturas }\end{array}$ \\
\hline$\frac{\text { El Profesional de la }}{\text { Información. }}$ & Espanha & $\begin{array}{c}\text { Ediciones Profesiona- } \\
\text { les de la Información } \\
\text { SL. }\end{array}$ & $\begin{array}{l}\text { APC para autores e taxa para publicar em } \\
\text { acesso aberto. }\end{array}$ \\
\hline Hermès. & França & --------- & -------------------------------- \\
\hline$\frac{\text { Informação \& Socieda- }}{\underline{\text { de (Ufpb. Online). }}}$ & Brasil & $\begin{array}{l}\text { Universidade Federal } \\
\text { da Paraíba. }\end{array}$ & $\begin{array}{l}\text { Sem APC. Gratuito para leitores. Agência de } \\
\text { fomento. }\end{array}$ \\
\hline$\frac{\text { Information, Communi- }}{\text { cation \& Society. }}$ & Inglaterra & Taylor \& Francis. & $\begin{array}{c}\text { APC apenas para acesso aberto e mantém- } \\
\text { se também através de assinaturas. É possível } \\
\text { pedir desconto conforme o nível do país do } \\
\text { autor. }\end{array}$ \\
\hline Information Research. & Suécia & University of Borås. & $\begin{array}{l}\text { Sem APC. Gratuito para leitores. Agência de } \\
\text { fomento. }\end{array}$ \\
\hline Information Sciences. & Holanda & Elsevier. & $\begin{array}{c}\text { APC apenas para acesso aberto. Mantém-se } \\
\text { através de assinaturas. }\end{array}$ \\
\hline International Journal of & EUA & University of & Sem APC. Gratuito para leitores. Agência de \\
\hline
\end{tabular}


Panorama dos modelos de negócios de periódicos científicos da área de Comunicação e Informação: classificação Qualis A1

\begin{tabular}{|c|c|c|c|}
\hline$\frac{\text { Communication (Onli- }}{\text { ne). }}$ & & Southern Carolina. & fomento. \\
\hline$\frac{\text { Investigación Bibliote- }}{\text { cológica. }}$ & México & $\begin{array}{l}\text { Universidad Nacional } \\
\text { Autónoma de México }\end{array}$ & $\begin{array}{l}\text { Sem APC. Gratuito para leitores. Agência de } \\
\text { fomento. }\end{array}$ \\
\hline $\begin{array}{l}\text { Journal of Computer- } \\
\text { Mediated Communica- } \\
\text { tion. }\end{array}$ & EUA & Wiley. & $\begin{array}{c}\text { APC apenas para acesso aberto. Mantém-se } \\
\text { através de assinaturas. }\end{array}$ \\
\hline$\frac{\text { Journal of Consumer }}{\text { Culture. }}$ & EUA & Sage publications. & $\begin{array}{c}\text { APC apenas para acesso aberto. Mantém-se } \\
\text { através de assinaturas. }\end{array}$ \\
\hline$\frac{\text { Journal of Cultural Heri- }}{\underline{\text { tage. }}}$ & Holanda & Elsevier. & $\begin{array}{c}\text { APC apenas para acesso aberto. Mantém-se } \\
\text { através de assinaturas. }\end{array}$ \\
\hline$\frac{\text { Journal of Documenta- }}{\underline{\text { tion. }}}$ & Inglaterra & $\begin{array}{l}\text { Emerald Publishing } \\
\text { Limited. }\end{array}$ & $\begin{array}{c}\text { APC apenas para acesso aberto. Mantém-se } \\
\text { através de assinaturas. }\end{array}$ \\
\hline $\begin{array}{l}\frac{\text { Journal of Librarianship }}{\text { and Information Scien- }} \\
\underline{\text { ce. }}\end{array}$ & EUA. & Sage publications. & $\begin{array}{c}\text { APC apenas para acesso aberto. Mantém-se } \\
\text { através de assinaturas. }\end{array}$ \\
\hline$\frac{\text { Journal of Scholarly }}{\text { Publishing. }}$ & Canadá & $\begin{array}{l}\text { Universidade de To- } \\
\text { ronto. }\end{array}$ & $\begin{array}{c}\text { APC apenas para acesso aberto e assinatu- } \\
\text { ras. }\end{array}$ \\
\hline $\begin{array}{l}\frac{\text { Journal of the American }}{\text { Society for Information }} \\
\frac{\text { Science and Technology }}{\text { (Online). }}\end{array}$ & EUA & Wiley. & $\begin{array}{c}\text { APC apenas para acesso aberto. Mantém-se } \\
\text { através de assinaturas. }\end{array}$ \\
\hline Journalism (London). & EUA & Sage publications. & $\begin{array}{l}\text { APC apenas para acesso aberto. Mantém-se } \\
\text { através de assinaturas. }\end{array}$ \\
\hline$\underline{\text { Journalism Studies. }}$ & Inglaterra & Taylor \& Francis. & $\begin{array}{l}\text { APC apenas para acesso aberto. É possível } \\
\text { pedir desconto conforme o nível do país do } \\
\text { autor. Mantém-se através de assinaturas. }\end{array}$ \\
\hline$\frac{\text { Knowledge Organizati- }}{\underline{\text { on. }}}$ & Alemanha & $\begin{array}{c}\text { Ergon Verlag/Nomos } \\
\text { Verlag. }\end{array}$ & $\begin{array}{c}\text { Se mantém através de assinaturas. O APC é } \\
\text { a própria assinatura. }\end{array}$ \\
\hline$\frac{\text { Latin American Rese- }}{\underline{\text { arch Review. }}}$ & EUA & $\begin{array}{l}\text { Latin American Studi- } \\
\quad \text { es Association }\end{array}$ & $\begin{array}{l}\text { Sem APC. Gratuito para leitores. Agência de } \\
\text { fomento. }\end{array}$ \\
\hline Libri (Copenhagen). & Alemanha & De Gruyter Saur. & $\begin{array}{c}\text { APC apenas para acesso aberto. Mantém-se } \\
\text { através de assinaturas. }\end{array}$ \\
\hline $\begin{array}{l}\text { Media, Culture \& Soci- } \\
\text { ety. }\end{array}$ & EUA & Sage publications. & $\begin{array}{c}\text { APC apenas para acesso aberto. Mantém-se } \\
\text { através de assinaturas. }\end{array}$ \\
\hline Memory Studies. & EUA & Sage publications. & $\begin{array}{l}\text { APC apenas para acesso aberto. Mantém-se } \\
\text { através de assinaturas. }\end{array}$ \\
\hline$\frac{\text { Museum History Jour- }}{\underline{\text { nal. }}}$ & Inglaterra & Taylor \& Francis. & $\begin{array}{l}\text { APC apenas para acesso aberto. É possível } \\
\text { pedir desconto conforme o nível do país do } \\
\text { autor. Mantém-se através de assinaturas. }\end{array}$ \\
\hline$\frac{\text { Perspectivas em Ciência }}{\text { Da Informação. }}$ & Brasil & $\begin{array}{l}\text { Universidade Federal } \\
\text { de Minas Gerais }\end{array}$ & $\begin{array}{l}\text { Sem APC. Gratuito para leitores. Agência de } \\
\text { fomento. }\end{array}$ \\
\hline
\end{tabular}




\begin{tabular}{|c|c|c|c|}
\hline $\begin{array}{l}\frac{\text { Revista Española de }}{\text { Documentación Cientí- }} \\
\underline{\text { fica. }}\end{array}$ & Espanha & $\begin{array}{l}\text { Consejo Superior de } \\
\text { Investigaciones Cien- } \\
\text { tíficas (CSIC). }\end{array}$ & $\begin{array}{l}\text { Sem APC. Gratuito para leitores. Agência de } \\
\text { fomento. }\end{array}$ \\
\hline Sage Open. & EUA & Sage publications. & Apenas APC. Gratuito para leitores. \\
\hline$\underline{\text { Social Semiotics. }}$ & Inglaterra & Taylor \& Francis. & $\begin{array}{l}\text { APC apenas para acesso aberto. É possível } \\
\text { pedir desconto conforme o nível do país do } \\
\text { autor. Mantém-se através de assinaturas. }\end{array}$ \\
\hline Sociétés (Paris). & França & De Boeck Supérieur. & Assinatura através dos usuários. Sem APC. \\
\hline $\begin{array}{l}\text { Studies in History and } \\
\text { Philosophy of Science. }\end{array}$ & Holanda & Elsevier. & $\begin{array}{c}\text { APC apenas para acesso aberto. Mantém-se } \\
\text { através de assinaturas. }\end{array}$ \\
\hline$\frac{\text { Television \& New Me- }}{\underline{\text { dia. }}}$ & EUA & Sage publications. & $\begin{array}{l}\text { APC apenas para acesso aberto. Gratuito } \\
\text { para a via verde, com um tempo de embar- } \\
\text { go a ser respeitado. Mantém-se através de } \\
\text { assinaturas. }\end{array}$ \\
\hline$\frac{\text { The South Atlantic }}{\text { Quarterly. }}$ & EUA & Universidade de Duke & $\begin{array}{l}\text { Sem APC. Gratuito para leitores. Mantém-se } \\
\text { através da assinatura de outros periódicos. }\end{array}$ \\
\hline Transinformação. & Brasil & PUCCampinas. & $\begin{array}{l}\text { Sem APC. Gratuito para leitores. Agência de } \\
\text { fomento. }\end{array}$ \\
\hline
\end{tabular}

Fonte: a autora, 2020.

Inicialmente, nota-se que dos 39 periódicos filtrados, 12 não possuem APC e funcionam em acesso aberto total; quatro deles são brasileiras, os outros dividem-se em quatro americanos, dois espanhóis espanholas, um mexicano e um sueco. Tal observação vai ao encontro da afirmação feita por Nassi-Caló (2013), na qual a autora expõe os dados de 2013 do Directory of Open Access Journals, onde o Brasil é o segundo lugar em publicações de qualidade publicadas em acesso aberto, ficando atrás apenas dos Estados Unidos. Desses 12 periódicos, 11 se encaixam em um arranjo de subsídio institucional, onde há verbas destinadas para esse periódico, com a participação voluntária, na qual a equipe editorial não recebe recursos diretos e atua de forma filantropa para a publicação do periódico. A única fora do padrão dito é o The South Atlantic Quaterly, cuja fonte de recursos se dá pelas assinaturas da versão impressa.

Constata-se também que todos os periódicos brasileiros presentes na listagem não possuem APC e recebem incentivos de agências de fomento do país, como a própria CAPES. O Brasil, sendo um dos maiores incentivadores do acesso aberto, promove a maior parte de sua literatura científica utilizando recursos públicos, contando com o trabalho voluntário dos pesquisadores e da infraestrutura das universidades públicas (APPEL; ALBAGLI, 2019). As informações mostradas no quadro estão de acordo com a pesquisa publicada pela ScienceMetrix (2018), uma empresa norte-americana independente especializada em avaliação de pesquisas, que afirma que entre 2011 e 2014, pelo menos 75\% dos artigos publicados (e que contenham pelo menos um autor brasileiro) estão disponíveis em acesso aberto através da via dourada. Diante dessa situação, estabelece-se o seguinte cenário: as pesquisas finan- 
ciadas por capital público deveriam disponibilizar seus resultados de forma pública e, por consequência, por livre acesso (KURAMOTO, 2006).

Dos 39 periódicos, 26 estão vinculados a editoras e, em sua maioria, pertencem a países desenvolvidos. Apesar do movimento de acesso aberto ter feito tanto cientistas quanto editoras repensarem o modo de fazer negócios na comunicação científica, ainda são as editoras comerciais que dominam o cenário editorial. Conforme as palavras de Gumieiro (2009), as editoras ainda estão presentes de forma dominante no cenário de publicações, regulando a difusão da ciência conforme a oscilação do mercado. $O$ aspecto financeiro, um dos tópicos levantados através da discussão sobre o acesso aberto, é um assunto preocupante para as editoras, visto que temem a redução de lucros no momento em que os leitores não precisam mais comprar acesso às publicações (BARCELLOS, 2016).

Dos 26 periódicos regidos por editoras, 25 pertencem a países desenvolvidos - também conhecidos como países centrais na área da publicação científica. Dados como esse só reforçam a ideia de que ainda há um interesse econômico por trás das publicações científicas, bem como nota-se que países centrais, nesse recorte, estão em maioria. Nesta situação, Meneghini (2012) coloca essa conjuntura de forma direta e clara: a motivação para produzir periódicos científicos em países em desenvolvimento (classificados como "periféricos" neste contexto) difere dos países centrais. Conforme o autor, "nestes, a força propulsora é primordialmente comercial, embora o interesse científico esteja necessariamente presente". Essa diferença salienta-se mais ainda quando todas as grandes editoras listadas no quadro apresentado (Sage publications, Elsevier, Wiley, Taylor \& Francis, Emerald) controlam as publicações dos países centrais, e todas funcionam através de uma combinação entre o modelo tradicional (acesso através de assinaturas) e o modelo APC, evidenciando que em casos como este, sempre haverá captação de recursos de algum lado, seja do usuário/cliente, ou do autor do artigo. Nesta conjuntura destaca-se a diferença entre países centrais e periféricos, posto que os primeiros possuem recursos para financiar a elaboração da pesquisa e a publicação dos resultados, enquanto os periféricos não possuem meios nem para o desenvolvimento pesquisa, nem para a comunicação dos resultados (COSTA, 2006).

Constata-se também que dos 39 periódicos identificados, 6 estão dispostos a reavaliar suas taxas de APC de acordo com o país do autor. Muito se fala sobre questões de desigualdade entre países periféricos e países centrais quando se cobram taxas para processamento de artigos, e que os primeiros sairiam prejudicados. Esse modelo de negócio se encaixaria como um APC ajustado, contemplando as diferenças de renda e fomento à pesquisa que cada país possui. Guedón (2010), por exemplo, sustenta que é importante que as taxas cobradas não condenem autores de países desfavorecidos para que assim não haja impedimento desses pesquisadores de terem seus trabalhos comunicados e reconhecidos.

\section{CONSIDERAÇÕES FINAIS}

Os resultados obtidos durante a pesquisa permitem evidenciar que, apesar da necessidade de reinvenção dos periódicos científicos de criar novos modelos de negócio para que os periódicos continuem ativos, e apesar das diferenças entre os países presentes no levantamento, o modelo tradicional de assinaturas ainda é predominante. Segundo Nassi-Caló (2013, online), as grandes editoras justificam essa atitude, pois "os maiores custos de publicação praticados pelas empresas comerciais de periódicos por assinatura são justificados por exercerem maior seletividade", ou seja, afirmam gastar mais com profissionais qualificados 
trabalhando no editorial do periódico para que isso a torne um produto de qualidade. Outro modelo prevalente foi o APC. Na dificuldade de fazer com que bibliotecas pagassem por assinaturas dos seus produtos, editoras resolveram passar o custo para que o autor disponibilize seu trabalho em acesso aberto. Conforme Vanz e Silva Filho (2019), esse tipo de modelo de negócio cresce aproximadamente $2 \%$ ao ano.

Também se confirmou na área de Comunicação e Informação, o quanto países da América Latina e Central (como Brasil e México) investem na iniciativa do acesso aberto através do fomento à pesquisa. Dados como esse corroboram o fato de que as pesquisas nesses locais são majoritariamente subsidiadas com recursos públicos, trabalho voluntário de profissionais e infraestrutura pública.

Apesar dos modelos ditos anteriormente estarem presentes de forma majoritária, é possível também identificar que aos poucos o mercado editorial nessa área, ainda que pouco, está tentando se reinventar ao repensar as taxas de publicação de forma mais justas para os pesquisadores de países periféricos. Esse ponto também pode demonstrar que, apesar da pequena variabilidade de modelos de negócios, as editoras estão começando a repensar de que forma seus modelos possam ser mais sustentáveis e convenientes financeiramente no movimento de acesso aberto, iniciativa que cresce entre as publicações científicas nacionais e internacionais a cada ano.

Ademais, as ponderações trazidas pelo presente artigo abrem portas para outros tipos de análises, sugerindo estudos mais aprofundados como a comparação de artigos publicados por ano, o tamanho da equipe editorial de cada periódico, as bases nas quais estão indexadas e até mesmo a apresentação de métricas alternativas. Todos esses aspectos podem ser relacionados com os modelos de negócios dos periódicos científicos, criando oportunidades de contribuições significativas para o tópico.

Em síntese ao trabalho elaborado, evidencia-se a importância da elaboração de pesquisas que tratem sobre modelos de negócio adotados por periódicos científicos, nacionais e internacionais. Por meio da elaboração desses estudos, cada vez mais apresentam-se caminhos alternativos ao modelo tradicional de publicação.

\section{REFERÊNCIAS}

ABADAL, Ernest. Retos de las revistas en acceso abierto: cantidad, calidad y sostenibilidad económica. Hipertext.net, [S. I.], 2012. Disponível em:

https://repositori.upf.edu/handle/10230/16413?locale-attribute=es. Acesso em: 01 fev. 2020.

ALVAREZ, Gonzalo Rubén; CAREGNATO, Sônia Elisa. A ciência da informação e sua contribuição para a avaliação do conhecimento científico. BIBLOS, [S. I.], v. 31, n. 1, p. 09-26, ago. 2017. Disponível em: https://periodicos.furg.br/biblos/article/view/5987/4618. Acesso em: 01 fev. 2020.

APPEL, André Luiz; ALBAGLI, Sarita. A adoção das taxas de processamento de artigos como modelo de negócios em periódicos brasileiros de acesso aberto.

Transinformação, Campinas, v. 31, 2019. Disponível em: https://brapci.inf.br/index.php/res/v/117209. Acesso em: 05 fev. 2020.

BARBOSA, Andreza Gonçalves et al. Evolução das funções dos periódicos científicos e suas 
aplicações no contexto atual. Múltiplos Olhares em Ciência da Informação, v.3, n.1, mar.2013. Disponível em: http://www.brapci.inf.br/index.php/res/download/78671. Acesso em: 03 fev. 2019.

BARCELLOS, Juliana Guerra de. Modelo de obtenção de verbas de periódicos brasileiros de acesso aberto das Ciências da Saúde indexados na Scielo. 2016. 87 f. TCC (Graduação) - Curso de Biblioteconomia, Universidade Federal do Rio Grande do Sul, Porto Alegre, 2016. Disponível em: https://lume.ufrgs.br/handle/10183/147253. Acesso em: 15 jan. 2022.

BIOJONE, Mariana Rocha. Os periódicos científicos na comunicação da ciência. São Paulo: EDUC/FAPESP, 2003.

BJÖRK, Bo-Christer; SOLOMON, David. The publishing delay in scholarly peer-reviewed journals. Journal of Informetrics, v. 7, n. 4, p. 914-923, out. 2013. Disponível em: https://www.sciencedirect.com/science/article/abs/pii/S1751157713000734?via\%3Dihub.

Acesso em: 15 jan. 2022

COSTA, Sely Maria de Souza. Filosofia aberta, modelos de negócios e agências de fomento: elementos essenciais a uma discussão sobre o acesso aberto à informação científica. Ciência da Informação, v. 35, n. 2, 2006. Disponível em:

https://brapci.inf.br/index.php/res/v/20705. Acesso em: 02 fev. 2022.

COSTA, Sely Maria de Souza, GUIMARÃES, Luisa Veras de Sandes. Qualidade de periódicos científicos eletrônicos brasileiros que utilizam o sistema eletrônico de editoração de revistas (seer). Inf. Inf., Londrina, v. 15, n. esp., p. 76-93, 2010.

Disponível em: http://www.uel.br/revistas/uel/index.php/informacao/article/view/5430. Acesso em: 06 fev. 2020

CROW, Raym. Income models for open access: an overview of current practice. Washington, D.C.: Scholarly Publishing \& Academic Resources Coalition, 2009.

Disponível em: https://sparcopen.org/wp-content/uploads/2016/01/incomemodels_v1.pdf. Acesso em: 05 fev. 2020.

DEZ ANOS DA Iniciativa de Budapeste em Acesso Aberto: a abertura como caminho a seguir.

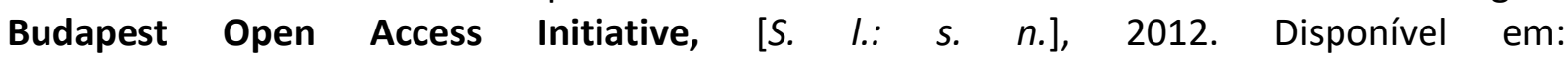
https://aberta.org.br/dez-anos-da-iniciativa-de-budapeste-em-acesso-aberto-a-aberturacomo-caminho-a-seguir/. Acesso em: 04 fev. 2020. 
GRUSZYNSKI, Ana Cláudia. GOLIN, Cida. Periódicos científicos nos suportes impresso e eletrônico: apontamentos para um estudo-piloto na UFRGS. Revista de Economía Política de las Tecnologías de la Información y Comunicación, v. 8, n. 2, maio/ago. 2006. Disponível em: https://seer.ufs.br/index.php/eptic/article/view/285/283. Acesso em: 04 jan. 2022.

GUANAES, Paulo Cezar Vieira; GUIMARÃES, Maria Cristina Soares. Modelos de gestão de revistas científicas: uma discussão necessária. Perspectivas em Ciência da Informação, Belo Horizonte, v. 17, n. 1, p. 56-73, 2012.

<http://www.scielo.br/scielo.php?script=sci_arttext\&pid=S141399362012000100004\&lng=e n\&nrm=iso. Acesso em: 12 jan. 2022.

GUÉDON, J. C. Acesso aberto e divisão entre ciência predominante e ciência periférica. In: FERREIRA, S. M.; TARGINO, M. das G. (Orgs.). Acessibilidade e visibilidade de revistas científicas eletrônicas. São Paulo: Editora São Paulo, 2010. p. 21-78.

GUMIEIRO, Katiúcia Araújo. Modelos de negócios para periódicos científicos eletrônicos de acesso aberto. 157 f. Dissertação (Mestrado em Ciências da Informação) - Programa de Pósgraduação em Ciências da Informação do Departamento de Ciências da Informação, Universidade de Brasília, Brasília, 2009. Disponível em:

https://repositorio.unb.br/bitstream/10482/3251/1/Katiucia_dissertacao.pdf. Acesso em: 05 fev. 2019.

GUMIEIRO, Katiucia Araujo; COSTA, Sely Maria de Souza. O uso de modelos de negócios por editoras de periódicos científicos eletrônicos de acesso aberto.

Perspectivas em Ciência da Informação, v.17, n.4, p.100-122, out./dez. 2012.

HARNAD, Stevan et al. The access/impact problem and the green and gold roads to open access. 2001. Disponível em:

https://www.tandfonline.com/doi/abs/10.1080/00987913.2004.10764930. Acesso em: 01 fev. 2020.

JACON, Maria do Carmo Moreira. Base Qualis e a indução do uso de periódicos da área de Psicologia. Transinformação, Campinas, v. 19, n. 2, p. 189-197, ago. 2007. Disponível em: https://www.scielo.br/scielo.php?pid=S0103-

37862007000200008\&script=sci_abstract\&tlng=pt. Acesso em: 01 fev. 2020.

KURAMOTO, Hélio. Informação científica: proposta de um novo modelo para o Brasil. Ciência da informação, Brasília, v. 35, n. 2, p. 91-102, maio/ago. 2006. Disponível em: https://www.scielo.br/i/ci/a/RcPCvVSyQ6dx7RcmJFLnbxL/abstract/?lang=pt. Acesso em: 13 jan. 2022

LEITE, Fernando César Lima. Gestão do conhecimento científico no contexto acadêmico: proposta de um modelo conceitual. 2006. XIII, 240 f. Dissertação (Mestrado em Ciência da Informação) - Universidade de Brasília, Brasília, 2006. Disponível em: https://repositorio.unb.br/handle/10482/3975. Acesso em: 16 dez. 2021 
MEADOWS, Jack. A comunicação científica. Brasília, DF: Briquet de Lemos, 1999. 268 p.

MORRISON, Heather et al. Open Access Article Processing Charges: DOAJ Survey May 2014. Publications, v. 3, n. 1, p. 1-16, maio 2015. Disponível em: https://doaj.org/article/27ee5b87d1b643e1b6241a064fb28e28. Acesso em: 08 jan. 2022.

MUELLER, Suzana Pinheiro Machado. A comunicação científica e o movimento de acesso livre ao conhecimento. Ci. Inf., Brasília, v. 35, n. 2, p. 27-38, ago. 2006.

Disponível em: https://www.scielo.br/scielo.php?pid=S0100-

19652006000200004\&script=sci_abstract\&tlng=pt. Acesso em: 01 fev. 2020.

NASSI-CALÒ, L. Avaliação por pares: modalidades, prós e contras. Blog SciELO em Perspectiva, [S. I.], 2015. Disponível em: https://blog.scielo.org/blog/2015/03/27/avaliacao-por-paresmodalidades-pros-e-contras/. Acesso em: 02 fev. 2020.

NASSI-CALÒ, Lilian. Quanto custa publicar em acesso aberto? In: Blog SciELO em Perspectiva, [S. I.], 2013. Disponível em: https://blog.scielo.org/blog/2013/09/18/quanto-custapublicar-em-acesso-aberto/. Acesso em: 04 fev. 2020.

PEREIRA, Vinícius; FURNIVAL, Ariadne Chloe. Revistas científicas em acesso aberto brasileiras no DOAJ. Brazilian Journal of Information Science, v. 14 No 1, n. 1, p. 88-111, 2020. Disponível em: https://brapci.inf.br/index.php/res/v/137445. Acesso em: 02 jan. 2022

[QUALIS PERIÓDICOS e classificação de produção intelectual]. CAPES, Brasília, [2019?]. Disponível em: https://sucupira.capes.gov.br/sucupira/public/index.jsf. Acesso em: 01 fev. 2020.

SANTILLÁN ALDANA, Julio Francisco. Modelos de negócio dos periódicos científicos de acesso aberto na América Latina e Caribe. 2014. 246 f., il.

Dissertação (Mestrado em Ciência da Informação) - Universidade de Brasília, Brasília, 2014. Disponível em: https://repositorio.unb.br/handle/10482/16386. Acesso em: 04 fev. 2020.

SCIENCE-METRIX (Canadá). Analytical support for bibliometrics indicators: open access availability of scientific publications. Montreal: Science- metrix, 2018. 36 p. Disponível em: https://www.science- metrix.com/sites/default/files/science-metrix/publications/sciencemetrix_open_access_availability_scientific_publications_report.pdf. Acesso em: $05 \mathrm{fev}$. 2020.

SIMEÃO, Elmira L. Melo S. A experiência da Revista de Biblioteconomia de Brasília na Internet. Revista de Biblioteconomia de Brasília, Brasília, v. 25, n. 1, 2001.

Disponível em: https://repositorio.unb.br/handle/10482/908. Acesso em: 04 fev. 2020.

SUBER, P. Open access overview: focusing on open access to peer-reviewed research articles and their preprints. 2004. Disponível em:

https://legacy.earlham.edu/ peters/fos/overview.htm. Acesso em: 04 jan. 2022.

SWAN, Alma. Diretrizes para políticas de desenvolvimento e promoção do acesso aberto. 
Brasília, DF: UNESCO Brasil, 2016. Disponível em:

https://unesdoc.unesco.org/ark:/48223/pf0000246018. Acesso em: 23 dez. 2021.

VANZ, Samile Andréa de Souza; SILVA FILHO, Rubens da Costa. O protagonismo das revistas na comunicação científica: histórico e evolução. In: CARNEIRO, Felipe Ferreira Barros; FERREIRA NETO, Amarílio; SANTOS, Wagner dos (org.). A comunicação científica em periódicos. Curitiba: Appris, 2019.

ZIMAN, J. Conhecimento público: a dimensão social da ciência. São Paulo: EDUSP, 1979.

WEITZEL, S. R. Iniciativa de arquivos abertos como nova forma de comunicação científica. In: SIMPÓSIO INTERNACIONAL DE BIBLIOTECAS DIGITAIS, 3., 2005, São Paulo. Anais eletrônicos... São Paulo: USP, 2005. Disponível em: http://eprints.rclis.org/6492/. Acesso em: 04 fev. 2020. 